\title{
THE SELECTIVE OXIDATION OF $N$-BUTANE TO MALEIC ANHYDRIDE; DEVELOPMENT OF SILICA-AND TITANIA SUPPORTED V-P-O CATALYSTS
}

\author{
MATTHIJS RUITENBEEK, R.A. OVERBEEK, D.C. \\ KONINGSBERGER AND J.W. GEUS \\ Utrecht University, Debye Institute, \\ Department of Inorganic Chemistry \\ PO Box 80083, 3508 TB Utrecht, The Netherlands \\ tel. $+31.30 .253 .6765 \mathrm{fax}+31.30 .251 .1027$ \\ m.ruitenbeek@anorg.chem.ruu.nl
}

\section{Introduction}

The selective oxidation of $n$-butane to maleic anhydride (Eq. 1) over catalysts based on V-P-O (Vanadium Phosphorus Oxide) is a commercially attractive route in view of the availability of $n$-butane and the carbon efficiency of the reaction. However, the $n$-butane content in the gas flow, containing oxygen, being passed over the catalyst, is restricted due to explosion danger $(1,2)$. The major part of the bulk V-P-O catalyst is formed by vanadylpyrophosphate, (VO) ${ }_{2} \mathrm{P}_{2} \mathrm{O}_{7}$, but evidence has been found that other (amorphous) V-P-O phases on the surface play an important role too (3).

Of great interest from an industrial point of view is the development of supported V-P-O catalysts and therefore we developed a method to prepare supported V-P-O catalysts on various supports. These catalysts have extensively been characterized and tested $(4,5)$. The new supported V-P-O catalysts show interesting properties like i) a well controlled and reproducible preparation procedure; $i$ i) a large surface area to make more active sites available; iii) a very short activation period; iv) a high attrition resistance, which makes them suitable for fluidized bed processes.

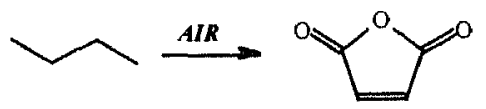

423

E. G. Derouane et al. (eds.), Catalytic Activation and Functionalisation of Light Alkanes, 423-427.

(C) 1998 Kluwer Academic Publishers. Printed in the Netherlands. 
The mechanism mostly assumed to be operative for selective catalytic oxidation over solid oxides is the Mars-Van-Krevelen mechanism, in which the catalyst is alternatively reduced by the compound to be oxidized and oxidized by gaseous molecular oxygen. It is important to assess whether the oxidation of $n$-butane over the selective V-P-O catalyst also proceeds via a Mars-VanKrevelen mechanism. When this mechanism is operative with the V-P-O catalyst, recirculation of the catalyst between a gas flow in which the catalyst is exposed exclusively to $n$-butane and one in which the catalyst is re-oxidized by gaseous oxygen, is viable. Recovery of the more concentrated maleic anhydride from the gas flow can be performed more easily and the risk of explosions is lower. Moreover, Gleaves et al. (6) have shown that passing a flow of ${ }^{18} \mathrm{O}_{2}$ and $n$-butane over the catalyst resulted in $\mathrm{C}^{18} \mathrm{O}^{18} \mathrm{O}$, which indicates that oxygen that is chemisorbed from the gas phase leads to a rapid non-selective oxidation. The authors used TAP (Temporal Analysis of Products) in their investigations. This rapid oxidation to carbon dioxide by oxygen, chemisorbed from the gas phase, suggests that, in the absence of gaseous oxygen, a higher selectivity can be achieved.

It is desirable that catalysts, to be used in assessing the mechanism of the oxidation of $n$-butane, exhibit a high surface-to-volume ratio of the active component, since the reduction of the catalyst may involve only (part of) the surface layer. Furthermore, the catalyst should preferably be active at low temperatures. Centi et al. (7) have observed that exposure of the usual bulk VP-O catalyst to $n$-butane at more elevated temperatures leads exclusively to desorption of carbon oxides. Reaction of $n$-butane with the surface in the absence of oxygen, or with an oxygen content too low to achieve oxidation of $n$ butane, causes carbon-containing species to be deposited on the surface of the catalyst. Exposure of the thus covered catalyst surface to molecular oxygen at temperatures of 400 to $450^{\circ} \mathrm{C}$, results in gaseous carbon oxides only. To investigate whether the adsorbed carbon-containing species can react with molecular oxygen to maleic anhydride calls for operation at lower temperature and, hence, for a catalyst being active at lower temperatures.

In this project, we investigated the mechanism of $n$-butane oxidation using a titania-supported V-P-O catalyst. A new procedure for the application of hydrated vanadia on the surface of supports involving $\mathrm{V}^{\mathrm{III}}$ was used to prepare titania-supported V-P-O catalysts of high activity (4). $\mathrm{V}^{\mathrm{III}}$ was produced via a scaled-up electrochemical reduction procedure of $V^{V}$ salts.

Using on-line mass spectrometry, the composition of effluent gas from the catalysts after reaction with consecutive pulses of $n$-butane and oxygen was analyzed. To establish the reduction of the active component, XANES (X-ray Absorption Near-Edge Structure) spectroscopy can be used (8). This technique provides information about the oxidation state of the vanadium (9-12). Furthermore, the characterization can be performed in-situ, and under well- 
defined reaction conditions. Since the titania-supported catalysts are welldispersed, the contribution of the (active) surface to the total spectrum is large. Therefore, the surface reactivity of the titania-supported V-P-O catalyst can be assessed with this technique.

Because of the high activity of the titania-supported catalysts, it was possible to use these in a separate reduction-oxidation process in which $n$-butane was adsorbed in absence of molecular oxygen at relatively low temperatures $( \pm$ $280^{\circ} \mathrm{C}$ ). In a second step, the catalyst was reoxidized in absence of $n$-butane leading to the selective formation MA. The selectivity to maleic anhydride was remarkably better in the oxidation-reduction process than under steady state conditions (13). A special titania-supported V-P-O catalyst has been prepared and characterized in-situ in the separate oxidation-reduction process with X-ray Absorption Spectroscopy (8).

XANES revealed that after a few reaction cycles, no more change in the valence state of vanadium occurs after reduction or reoxidation of the sample. This indicates that the generally assumed Mars-Van-Krevelen mechanism is not operative for this catalyst.

Recently, we started the analysis of the EXAFS (Extended X-ray Absorption Fine Structure) part of the X-ray absorption data. Figure 1 shows the Fourier transform of the raw data of a typical equilibrated bulk catalyst and a titaniasupported catalyst.

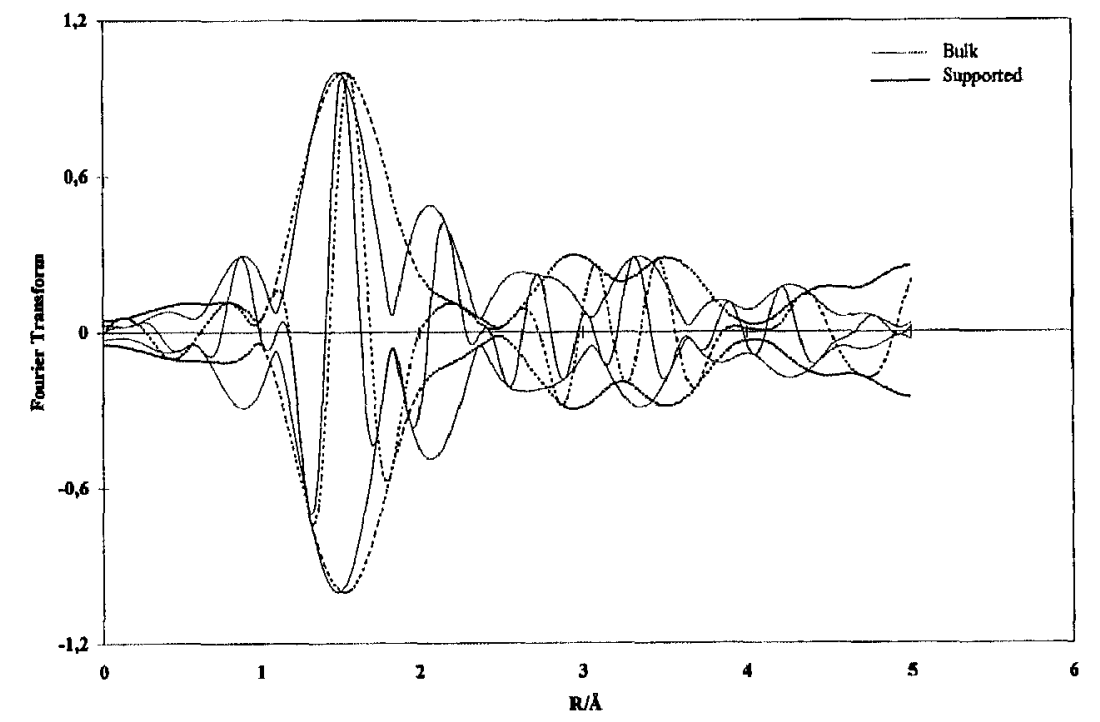

Figure 1. Fourier Transformation $\left(\mathrm{k}^{2}, \Delta \mathrm{k}=3-11 \AA^{-1}\right)$ of an equilibrated (organic preparation) bulk catalyst (dotted line) and a titania-supported catalyst (solid line). Spectra were recorded in $\mathrm{He}$ at $-196^{\circ} \mathrm{C}$ at the SRS in Daresbury (UK), station 8.1 
It is obvious that the structure of the titania-supported catalysts is completely different from the structure of a bulk V-P-O catalysts. Furthermore, large differences in the local environment of vanadium were observed during the sequential steps in the earlier described reduction-reoxidation process.

Data were fitted in $R$-space by means of the difference-file technique with an in-house developed computer program, $\operatorname{XDAP}(14,15)$. Results of the fits of two bulk V-P-O catalysts, prepared in organic and in aqueous media are in good agreements with crystallographic data (16). In Table 1, the EXAFS results of an organic bulk catalysts as well as the results of a titania-supported V-P-O catalysts $(8.2 w t . \% \mathrm{~V})$ are represented.

Table 1. Atomic distances, coordination numbers and Debye-Waller factors of an equilibrated bulk catalyst (organic preparation) and a titania-supported catalyst. Input data for the bulk catalyst were fixed and taken from (16).

\begin{tabular}{l|ccc|ccc}
\hline & $\begin{array}{c}\text { Bulk } \\
\mathrm{R}(\AA)\end{array}$ & $\mathrm{N}$ & $\Delta \sigma^{2}$ & $\begin{array}{c}\text { Supported } \\
\mathrm{R}(\AA)\end{array}$ & $\mathrm{N}$ & $\Delta \sigma^{2}$ \\
\hline $\mathrm{V}-\mathrm{O}_{1}$ & 1.59 & 1 & 0.00347 & 1.59 & 1.11 & 0.00165 \\
$\mathrm{~V}-\mathrm{O}_{2}$ & 1.94 & 2 & -0.00199 & 1.92 & 1.92 & -0.00504 \\
$\mathrm{~V}^{-} \mathrm{O}_{3}$ & 2.07 & 2 & 0.00465 & - & & \\
$\mathrm{V}^{-} \mathrm{O}_{4}$ & 2.36 & 1 & 0.00330 & - & & \\
$\mathrm{V}-\mathrm{O}_{5}$ & & & & 2.58 & 2.01 & -0.00313 \\
$\mathrm{~V}-\mathrm{V}$ & 3.23 & 1 & 0.01592 & - & & \\
$\mathrm{V}-\mathrm{P}$ & 3.33 & 4 & 0.00400 & 3.42 & 3.23 & 0.00944 \\
\hline
\end{tabular}

The experimental data for the titania-supported catalyst gave a satisfactory fit for all spectra. A comparison between the structure of bulk V-P-O and the titania-supported V-P-O catalyst under reaction conditions in the different steps of the reduction-oxidation process will be discussed. Furthermore, it will be shown that EXAFS gives important information about the type of oxygen that is consumed during the oxidation/reduction process.

\section{References}

1. G. Centi, F. Trifiro, J.R. Ebner, and V.M. Franchetti, Chem. Rev. 88 (1988), 55.

2. Vanadylpyrophosphate Catalysts, ed. G. Centi, Catal. Today 16 (1993), 1.

3. R.A. Overbeek, M. Ruitenbeek, R.T. Wegh, M. Versluijs-Helder, A.J. van Dillen, and J.W. Geus, submitted to J.Catal.

4. R.A. Overbeek, P.A. Warringa, M.J.D. Crombag, L.M. Visser, A.J. van Dillen, and J.W. Geus, Appl. Catal. A: General 135 (1996), 209-230. 
5. R.A. Overbeek, A.R.C.J. Pekelharing, A.J. van Dillen, and J.W. Geus, Appl. Catal. A: General 135 (1996), 231-248.

6. J.T. Gleaves, J.R. Ebner, T.C. Kuechler, Catal. Rev. Sc. Eng. 30(1) (1988), 49.

7. G. Centi, F. Trifiro, G. Busca, J. Ebner, J. Gleaves, Disc. Faraday Soc. 87 (1989), 215.

8. M. Ruitenbeek, R.A. Overbeek, A.J. van Dillen, D.C Koningsberger, J.W. Geus, Recl. Trav. Chim. Pays-Bas 115 (1996), 519.

9. J. Wong, F.W. Lytle, R.P. Mesmer, D.H. Maylotte, Phys. Rev. B. 30 (1984), 5596.

10. J. Wong, D.H. Maylotte, F.W. Lytle, R.B. Greegor, R.L. St. Peeters, in "EXAFS and Near Edge Structure", A. Bianconi, L. Inoccia and S. Stipcich, eds., Springer Verlag, Berlin, 1983, p. 206.

11. J. Wong, R.P. Mesmer, D.H. Maylotte, in "EXAFS and Near Edge Structure", A. Bianconi, L. Inoccia and S. Stipcich, eds., Springer Verlag, Berlin, 1983, p. 130.

12. I. Davoli, S. Stizza, M. Benfatto, O. Gzowiski, L. Murawski, A. Bianconi, in "EXAFS and Near Edge Structure", A. Bianconi, L. Inoccia and S. Stipcich, eds., Springer Verlag, Berlin, 1983, p. 162.

13. M.Ruitenbeek, R.A. Overbeek, L.M. Visser, A.J. van Dillen, D.C. Koningsberger, J.W. Geus, to be published in Catal. Letters.

14. M. Vaarkamp, J.C. Linders, D.C. Koningsberger, Physica B (1995), 208.

15. M. Vaarkamp, J.C. Linders, D.C. Koningsberger, Proc. XAFS VIII, Berlin, 159.

16. P.T. Nguyen, R.D. Hoffman, A.W. Sleight, Mat. Res. Bull. 30 (1995), 1055. 